The oxidation of organic compounds by metal ions and complexes was reviewed by $H$. R. Bacon with particular reference to complexes of silver and copper. Recent work using argentic piccolinates to catalyse the oxidation of primary and secondary amines has indicated that the effectiveness of the metal ion may be modified by the nature of the ligand. Comparison of reactions catalysed by cobalt, silver and copper complexes may lead to a better understanding of the reaction mechanism.
The conference concluded with a general discussion of the relative merits of fluidized-bed versus fixed-bed reactors for oxidation reactions. For those reactions, such as the modified Deacon process, in which thermal balance is readily achieved, the fluidized process is preferable. In reactions liable to rapid heat evolution, leading to possible explosion hazard, fixed-bed reactors may be preferred although sufficient data on the successful application of the fluidized technique to such reactions are not yet available. F. Monton

\title{
FAST REACTIONS IN PHYSICAL CHEMISTRY
}

T HE first of the triennial Cambridge Physical Chemistry Summer Schools was held in August 1947 but the sequence was broken after 1956 by a gap of five years.

Each school has been organized by Prof. R. G. W. Norrish and his colleagues in the Department of Physical Chemistry in Cambridge and this year Dr. A. B. Callear and Dr. B. P. Levitt acted as organizers. The topics were selected to form a composite pattern of ideas related to current researches in the Department. Certain lecturers belonged to the Department; others were guest lecturers.

The intention has always been to correlate facts and notions within the pattern chosen, to stimulate discussion, to invite, even to provoke, in a friendly way controversy, rather than to instruct by presenting the facts, figures and theory as finished uninspir. ing blocks of knowledge which could well be posted in cyclostyled form. The pattern for the 1961 School was "The Study of Fast Reactions".

Dr. T. M. Sugden (Cambridge) dealt effectively with the recent developments in the collision and transition state theories, a matter of constant concern with so many chemists in industry and college alike. In his energetic, elusively 'off the cuff' manner, he analysed the processes of energy exchange with special reference to fast reactions, unimolecular decomposition of polyatomic molecules and the recombination of atoms. It may be well imagined that there was much animated discussion during the halfhour coffee-break.

Dr. Sugden described the photometric investigation of flames. He referred to experimental techniques for the measurements of $\mathrm{H}$-atom, O-atom and $\mathrm{OH}$ - group concentrations in flames. Significances of the method included the determination of bond strengths in molecules such as $M-\mathrm{Cl}, M=\mathrm{Mn}$, $\mathrm{Ni}$, etc. Trends into the future were not neglected. In another talk, Dr. Sugden dealt with chemical reactions in the upper atmosphere. Methods of investigation of temperature, density, pressure, and composition gradients and the reactions occurring in different strata are bound to attract quickly growing interest in coming years.

Reactions in shock waves were discussed by Dr. A. G. Gaydon (Imperial College of Science and Technology), who outlined experimental methods of observing the emission spectra and temperatures of shock-heated gases. Vibrational relaxation times of nitrogen and carbon monoxide, and the measurement of dissociation-rates of oxygen, hydrogen and carbon dioxide were other points of lively interest to the non-expert as well as to the expert listener. In another lecture, Dr. Gaydon discussed the advantages of low-pressure flames for the study of reaction zones, referring to the identification of reactive intermediates by emission spectra of flames, to the measurement of temperature by study of rotational structure of bands, the reversal of spectral lines and to reactions in hydrocarbon flames.

Chain reactions in gases, especially those leading to the ignition of gases, were discussed by Dr. P. G. Ashmore (Cambridge), who has taken part in a number of previous Schools. Theories of ignition limits and of induction periods were discussed with reference to non-branching and branching chain reactions.

Ultra-violet spectroscopy and fluorescence was dealt with by Dr. A. B. Callear (Cambridge), who opened with a helpful reminder on the use of term symbols and mode of coupling of angular momenta in atoms. Information on spin-orbit relaxation can be gained from examination of the quenching of the fluorescence of sodium and mercury. Rate of vibra. tional relaxation of electronically excited $I_{2}, S_{2}$ and NO was referred to.

Evidence for ions in flames was presented by Dr. D. R. Jenkins (Cambridge), who outlined experimental methods for the determination of distribution of ions by means of Langmuir probes, microwave and radiowave attenuation and mass spectroscopy.

Relaxation in liquids was the title of a lecture by Prof. J. Lamb (Imperial College of Science and Technology), who outlined the fundamental theory of acoustic relaxation to what must have been many new attentive ears. The potentialities of the method were amply illustrated in a very convincing way.

Techniques for the measurements of fast reactions in solution were considered by Dr. R. H. Prince (Cambridge), who gave a lucid survey of mechanism and reactivity revealed by a study of fast reactions in solution. Substitution reactions in organometallic and co-ordination compounds; redox reactions, rapid isotope exchange were mentioned in particular.

Kinetics of fast reactions in solution was the title of the lecture by Dr. E. A. Moelwyn-Hughes (Cambridge), who, in his inimitable and stimulating way. brought freshness to the ever-difficult problems of rate data and transition-state characteristics. Interpretation of rate data as a function of temperature, certain limitations of the transition state formulation and the derivation of equations used in the interpretation of relaxation of ionic equilibria were critically cormmented on.

The lecture on fast electrode reactions by Dr. G. C. Barker (Atomic Energy Research Establishment, Harwell) was a very helpful contribution. He considered the theoretical basis of the measurement of rapid redox reactions which occur at the electrolyte/ electrode interface and remarked in useful detail on 
experimental methods involving single-step squarewave pulses and Faradaic rectification.

Not quite in the pattern but timely and very helpful was the talk on high-speed gas chromatography by Dr. J. H. Purnell (Cambridge). Factors determining the correlation between the speed of a gas chromatographic analysis and the efficiency of the process were examined in a cursive and conciliatory way, appropriate in dealing with a technique which is still much of an art. If necessary, remurkably short analysis times, less than 1 sec., could be achieved, and are attractive in the study of gas reactions.

Work on isothermal reactions of atoms and radicals by flash photolysis was discussed by Prof. R. G. W. Norrish, who illustrated the applicability of the techniques of flash photolysis in the detailed scrutiny of very fast reactions in gases. In the last lecture of the School, he went into the matter of the chemistry of combustion as revealed by kinetic spectroscopy, showing the applicability of flash photolysis in the investigation of adiabatic processes. Anti-knock action of tetraethyl lead was related to the appearance and disappearance of lead oxide and lead during explosion.

Time for discussion was allowed at the end of each lecture and indeed there were some astute points put. There was animated and valuable discussion during the long coffee-break in the morning and during the afternoons, which were in the main devoted to visits to the laboratories and to a lecture at 5-6 p.m. There were social meetings when easy exchange of ideas was stimulated.

An outstanding feature was the well-organized social life of the School, and in this Mrs. Norrish and other ladies had doubtless been influential. There were some 120 members from industry and colleges and quite a number were from overseas. W. Gerrard

\section{METALLURGY OF BERYLLIUM}

$\mathrm{B}$ ERYLLIUM has only emerged as a metal of industrial significance during the past few years. Even now, its use is not securely established and is faced by a number of real difficulties. The following assessment of its present position is based on seventy papers presented at an international conference arranged by the Nuclear Energy Committee of the Institute of Metals and held in London during October 16-18.

The potential applications of beryllium at present lie in two main fields-aircraft, missiles and spacecraft on the one hand, and atomic reactors on the other. In the first, the advantageous properties of beryllium are its high-strength-to-weight ratio, high elastic modulus, specific heat and thermal conductivity and moderately low coefficient of expansion. With a density of $\mathbf{1 . 8 5}$ and a tensile strength of 50-70,000 lb./sq. in., beryllium has a superior strength/ weight ratio to all other metals up to about $350^{\circ} \mathrm{C}$., although some of the recently developed high-strength stainless steels are not far behind. However, this is not beryllium's greatest attraction. Elastic stiffness and resistance to buckling under compression rather than tensile properties are the limiting factors in many design problems in this aeronautical and spacecraft field, and it is in this that beryllium's combination of low density and high modulus of elasticity ( $E=43 \times 10^{6} \mathrm{Ib}$./sq. in.) is outstanding. Thus, for example, a box beam designed in beryllium to resist a buckling load at up to $450^{\circ} \mathrm{C}$. is only about half as heavy as one in titanium alloy and about one-third as heavy as one in a high-strength stainless steel. In addition, the high specific heat and thermal conductivity and the low coefficient of expansion are important in minimizing the effects of aerodynamic heating. With these properties, "beryllium holds one of the keys to a successful flight to the moon" (I. Perlmutter, Wright-Patterson Air Force Base).

For atomic reactors, on the other hand, the attraction of beryllium lies in its low neutron adsorption, and at present there is wide investigation of its possible use as the fuel element can in high-temperature, gas-cooled reactors. In addition, the Australian Atomic Energy Commission is examining the use of beryllium, instead of graphite, as a moderator in low-power reactors on the grounds that this would permit smaller reactor cores and possibly reduce over-all cost. It is also considering fuel elements in which the fuel, for example $(\mathrm{U}, \mathrm{Th}) \mathrm{Be}_{18}$, is dispersed in beryllium.

Unfortunately, these attractive properties are accompanied by two immediate disadvantages. Beryllium is very costly; billets are about $£ 20$ per lb. The United Kingdom is not a producer; supplies come from Pechiney and from the United States. Secondly, there is a severe health hazard. Inhalation of the metal or its compounds produces acute chemical pneumonitis, or, at lower doses, a chronic lung disease, berylliosis. To keep the beryllium content of the air at safe levels, special workshops are required with air extraction and filtration, and total enclosure of some machines. Monitoring of the beryllium-levels and health checks are necessary. However, the applications suggested for beryllium are those that can withstand a fairly high cost and, once a beryllium-handling facility has been established, the health-hazard is not too troublesome. There remains a third disadvantage, that of brittleness, and at present this is the major problem in the metallurgy of beryllium. Practically every paper read at the conference in London was to some extent concerned with brittleness.

Beryllium is quite ductile at normal hot-working temperatures of $1,000^{\circ}-1,050^{\circ}$ C., so hot-fabrication processes do not present any great difficulty. However, below about $200^{\circ} \mathrm{C}$. there is a fairly sharp transition to a low ductility. This not only means that fabrication by cold-work is difficult or impossible, but also, and more important, that in service high stresses, perhaps purely local, that might be relieved by plastic distortion, lead instead to fracture.

This transition to brittleness is accompanied by a transition in fracture mode from so-called 'ductile fracture' to a process of separation along definite crystallographic planes, the cleavage planes. Thus, the brittleness of beryllium appears to correspond to the classical brittle fracture of mild steel that has caused so much concern and investigation since the 'Liberty' ship failures during the War.

Investigations of mild steel have brought out the importance of two stages in the development of cleavage. First, the initiation of a crack by some 